\title{
The Overall Survival Benefit for Patients with T1 Renal Cell Carcinoma after Nephron-Sparing Surgery Depends on Gender and Age
}

\author{
A Retrospective Multi-Centre Study Comparing the Overall Survival Benefit of Patients with T1 \\ Renal Cell Carcinoma Undergoing Either Radical Nephrectomy or Partial Nephrectomy in Order \\ to the Age and the Gender of the Patients
}

\author{
Elisabeth Liek ${ }^{\mathrm{a}}$ Heiko Wunderlich ${ }^{\mathrm{a}}$ Klaus Elsebach $^{\mathrm{b}}$ Hubert Göbel $^{\mathrm{c}}$ \\ Xaver Krah ${ }^{d}$ Andreas W. Krautschick-Wilkens ${ }^{e}$ Josef Schweiger ${ }^{f}$ Gabriel Steiner $^{g}$ \\ Thomas Steiner $^{\text {h J Joana Heinzelmann }}{ }^{\mathrm{i}}$ \\ ${ }^{a}$ Department of Urology, St. Georg Clinic Eisenach, Eisenach, Germany; ${ }^{b}$ Department of Urology, Ilm-Kreis- Clinic \\ IImenau, IImenau, Germany; ${ }^{\mathrm{C}}$ Tumorzentrum Erfurt, Erfurt, Germany; ${ }^{\mathrm{d}}$ Department of Urology, Helios Clinic Blankenhain, \\ Blankenhain, Germany; ${ }^{\mathrm{e} D e p a r t m e n t}$ of Urology, Helios Clinic Gotha, Gotha, Germany; ${ }^{\mathrm{f}}$ Department of Urology, Catholic \\ Hospital St. Johann Nepomuk Erfurt, Erfurt, Germany; ${ }^{9}$ Department of Urology, Helios Clinic Meiningen, Meiningen,

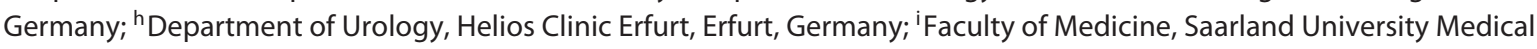 \\ Center and Saarland University, Homburg, Germany
}

\section{Keywords}

Renal cell carcinoma · Nephrectomy · Partial nephrectomy · Age $\cdot$ Gender $\cdot$ Overall survival

\footnotetext{
Abstract

Due to the recommendations in the urological guidelines to perform nephron-sparing surgery in patients with organconfined renal cell carcinoma (RCC), the customary therapy regimen changed, but it is not well studied yet whether partial nephrectomy (PN) especially in the elderly is beneficial. From 2000 to 2015, 3,592 patients from 7 clinics undergoing surgery in RCC were identified; 2,323 had T1 tumours. We
}

retrospectively compared the overall survival benefit of patients with T1 RCC who underwent either PN or radical nephrectomy (RN) and studied effects of age and gender. $\boldsymbol{R} \boldsymbol{e}$ sults: In T1 RCC, PN was beneficial in male patients ( $p=$ 0.0006 ) independent of age, especially in those men $\leq 75$ years of age ( $p=0.0005)$; but PN was not beneficial for female patients ( $p=0.0629$ ) regardless of age and male patients older than 75 years $(p=0.736)$. The OS of female patients after $\mathrm{RN}$ and male patients after $\mathrm{PN}$ is the same, regardless of age. A life expectancy of more than 45 months at least is neces-

E.L. and H.W. contributed equally to this work. H.W., T.S., and J.H. are part of the "German Network Renal Cell Tumors".

\section{KARGER}

(C) 2018 S. Karger AG, Basel

E-Mail karger@karger.com

www.karger.com/uin
Elisabeth Liek, MD

Department of Urology

St. Georg Clinic

DE-99817 Eisenach (Germany)

E-Mail Elisabeth.Liek@gmx.de 
sary to experience an overall survival benefit after PN. Conclusions: There should be harder proven indications for PN in female patients and especially in all patients older than 75 years, particularly with regard to perioperative risk factors.

(c) 2018 S. Karger AG, Basel

\section{Introduction}

Within the last 2 decades, many studies reported a benefit of a partial nephrectomy (PN) in comparison to radical nephrectomy $(\mathrm{RN})$ in patients with $\mathrm{T} 1$ renal cell carcinoma (RCC). Equal oncologic outcome [1-4] could be shown by both surgical treatments with, for example, an increase in overall mortality and non-cancer-related death rates in patients treated by nephrectomy [5-7]. Consequently, international guidelines were adapted regarding the recommendations of surgical treatment in pT1 RCC. The EAU defined PN as the standard procedure in the treatment of RCC smaller than $4 \mathrm{~cm}$ in their guidelines, which was reconfirmed in the 2016 update [ 8 , 9]. The latest German $S 3$ guidelines for RCC followed this recommendation and rated it with a grade A level of evidence [10].

Most studies on which these guideline recommendations rely, only analyzed the positive effect of PN regardless of age. There is little evidence concerning the overall survival benefit after PN or RN in patients with small RCC in relation to patient age. Sun et al. [11] and some more $[11,12]$ reported about an equal other-cause mortality (OCM) rate in older and ill patients treated either by $\mathrm{PN}$ or RN and a loss of protective effect of PN in OCM. A subgroup analysis of Tan et al. [13] has shown the greatest survival benefit with $\mathrm{PN}$ for patients aged less than 75 years.

The aim of this study was to depict the benefit of PN versus $\mathrm{RN}$ in T1 RCC on overall survival rate and to further analyze the effects of age and gender. Towards achieving this, data from the cancer database of west- and mid-Thuringia has been analyzed.

\section{Material and Methods}

For our retrospective analysis we used data from the west- and mid-Thuringian cancer database located in Erfurt to which 7 local urological clinics send their data. The registries include the clinics of Blankenhain, Eisenach, Erfurt (Helios Clinic Erfurt, Catholic Hospital Erfurt), Gotha, Ilmenau, Meiningen.

We used the ICD-O diagnostic code (C64) as inclusion criteria. The differentiation between the operation methods especially either radical or PN was performed in use of the OPS code system.
We retrospectively analyzed the data of pT1 RCC patients including age, gender, tumour stage, surgical method and overall survival. Within the observation period from 2000 to 2017, 152 (14.7) and 383 (31.7\%) patients treated with PN and RN died, respectively.

The mean follow-up was 57 (0-198) months for PN and 84 (0-203) months for RN. The reason for the different follow-up is the change of operative procedure from radical to PN for T1 RCC over time. Except for 35 cases, all PN were performed by open surgery. Because of the small number of cases, these patients were excluded from statistical evaluation. No robotic-assisted advice was used.

We tested the effect of surgery (PN vs. RN) on the endpoint of death (overall survival) by Kaplan-Meier estimates (product-limit estimates). The survival distributions of 2 samples were compared with the log-rank test. For the calculation we used the procedure LIFETEST of the statistical software SAS (R) version 9.2.

\section{Results}

Between 2000 and 2015, the number of oncological surgeries performed on patients with RCC was 3,592; out of these, $2,323(64.7 \%) / 208(5.8 \%) / 977(27.0 \%) / 36(1.0 \%)$ pT1/pT2/pT3/pT4 tumours, respectively (Fig. 1). In 2015, nephron-sparing surgery was performed in $19.3 \%$ (2005), $34.6 \%$ (2010) and up to $59.3 \%$ over all tumour stages. Especially in the target group of pT1 tumours (2242 evaluated patients), the rate of $\mathrm{PN}$ (1,032 patients) increased from $27.0 \%$ in 2005 to $82.3 \%$ in 2015 .

Finally, 2,242 patients who underwent surgery with histopathologically confirmed pT1 RCC were included 1,443 male and 799 females. Of these, 1,032 patients were treated by PN and 1,210 by RN (Fig. 1,2). The mean overall age was 64.8 years (SD 10.6) - male patients were 64.0 years (SD 10.3) and female patients were 66.1 years (SD 11.1).

Regardless of age and gender, there was an overall survival benefit for all patients treated by $\mathrm{PN}(p=0.0002$; Fig. 3). But this significant overall survival benefit was seen only in male patients $(p=0.0006)$. In female patients, there was no significant outcome benefit $(p=0.0629)$, regardless of the age.

Based on the age of the patients, only male patients $\leq 75$ years of age showed a significant overall survival benefit ( $p=0.0005)$ for PN. In male patients older than 75 years, a survival benefit was not found ( $p=0.736$; Fig. 4 ). In female patients $\leq 75$ years as well as in female patients older than 75 years, there was no statistically significant benefit in overall survival for PN (female $\leq 75$ years: $p=0.175$, female $>75$ years: $p=0.191$ ) at all (Fig. 5). Male and female patients older than 75 years showed the same prognostic data, both for radical and for $\mathrm{PN}$, regardless of the 
Fig. 1. Overview of surgeries in RCC from 2000 to 2015 (48 tumours were without classification, $1.5 \%)$.

Fig. 2. Overview of eligible and treated patients in order to gender, age and surgical technique. $y$, years.

Fig. 3. Overall survival of all T1 RCC patients after both radical and partial nephrectomy.
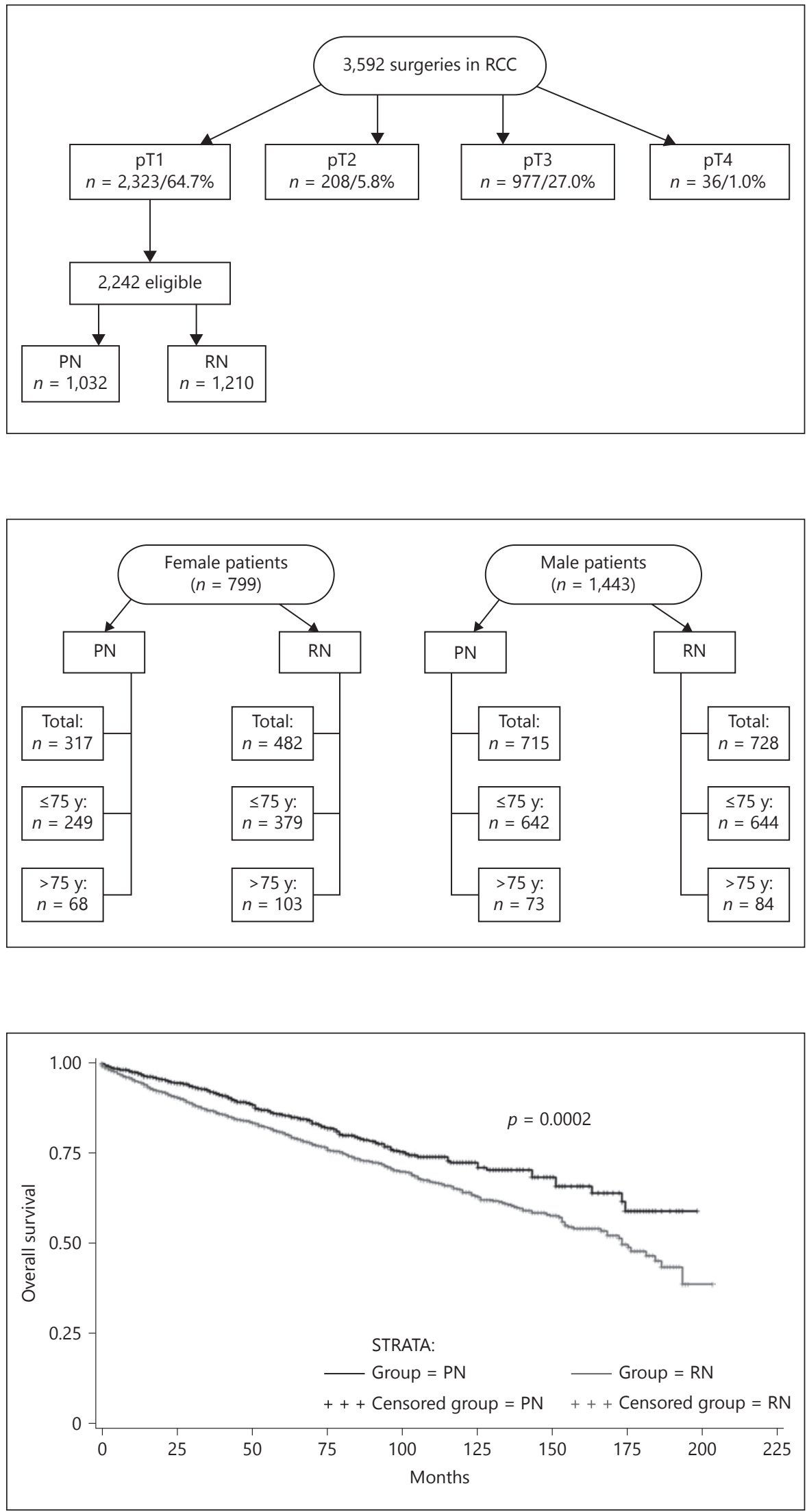

Urol Int 
Fig. 4. Overall survival of male patients $\leq 75$ and $>75$ years.

Fig. 5. Overall survival of female patients $\leq 75$ and $>75$ years.
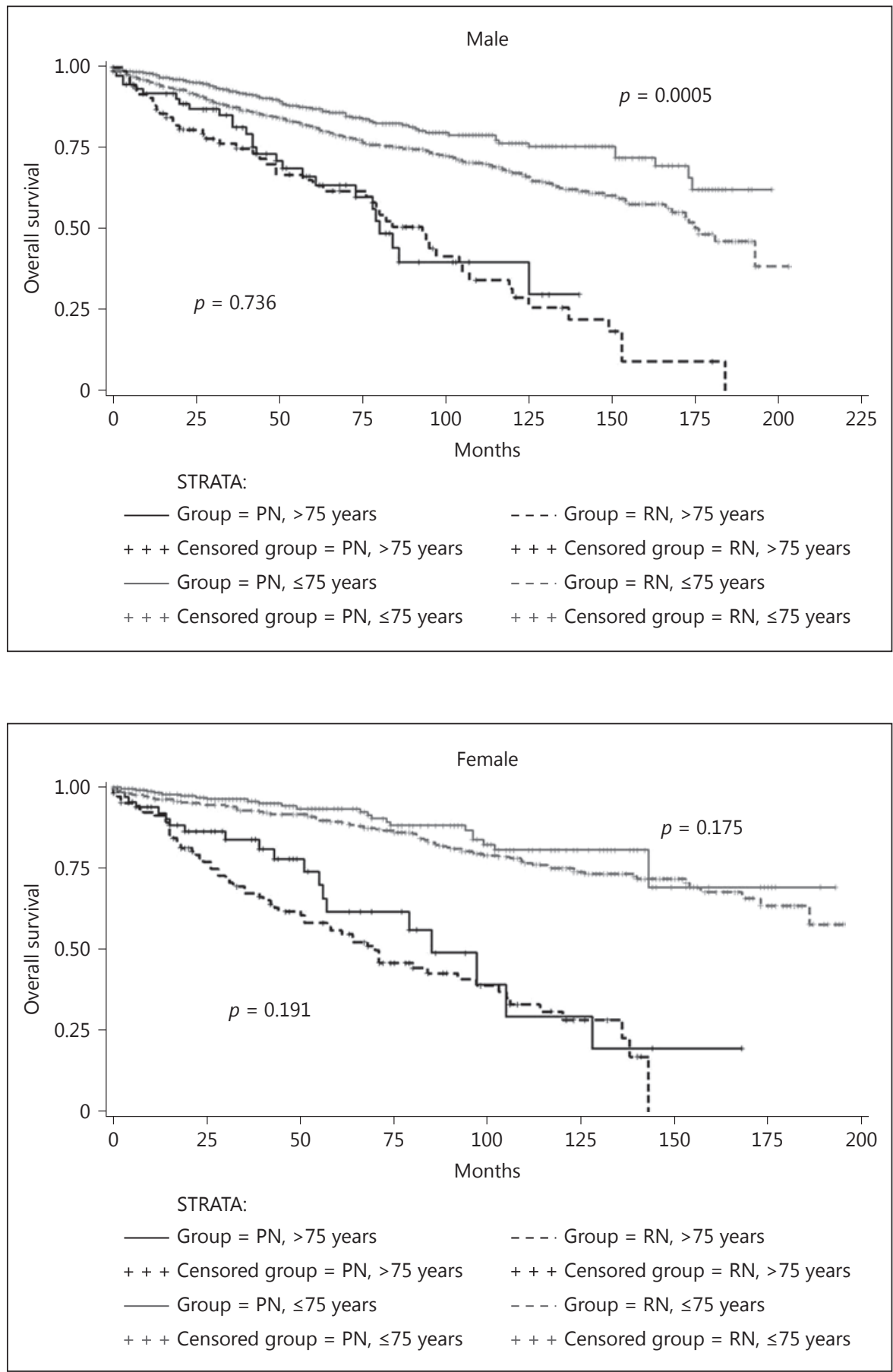

gender (Fig. 6). All female patients $\leq 75$ years (both treated by radical or $\mathrm{PN}$ ) as well as male patients $\leq 75$ years after nephron-sparing surgery were found to be in similar status in terms of overall survival. There was no statistical difference. But male patients $\leq 75$ years of age with $\mathrm{RN}$ in T1 RCC showed significantly the worst overall survival (Fig. 7).
The comparison of the follow-up data from patients treated with PN (group 1: 2000-2005 and group 2: $2006-$ $2015)$ is shown in Figure $8(p=0.3814)$. Figures 9 and 10 show the comparison of overall survival both after partial and $\mathrm{RN}$ in different periods (Fig. 9: 2000-2005, $p=0.0043$ and Fig. 10: 2006-2015, $p=0.175$ ). 
Fig. 6. Overall survival of male and female patients $>75$ years.

Fig. 7. Overall survival of male and female patients $\leq 75$ years.

T1 RCC after Nephron-Sparing Surgery Depends on Gender and Age
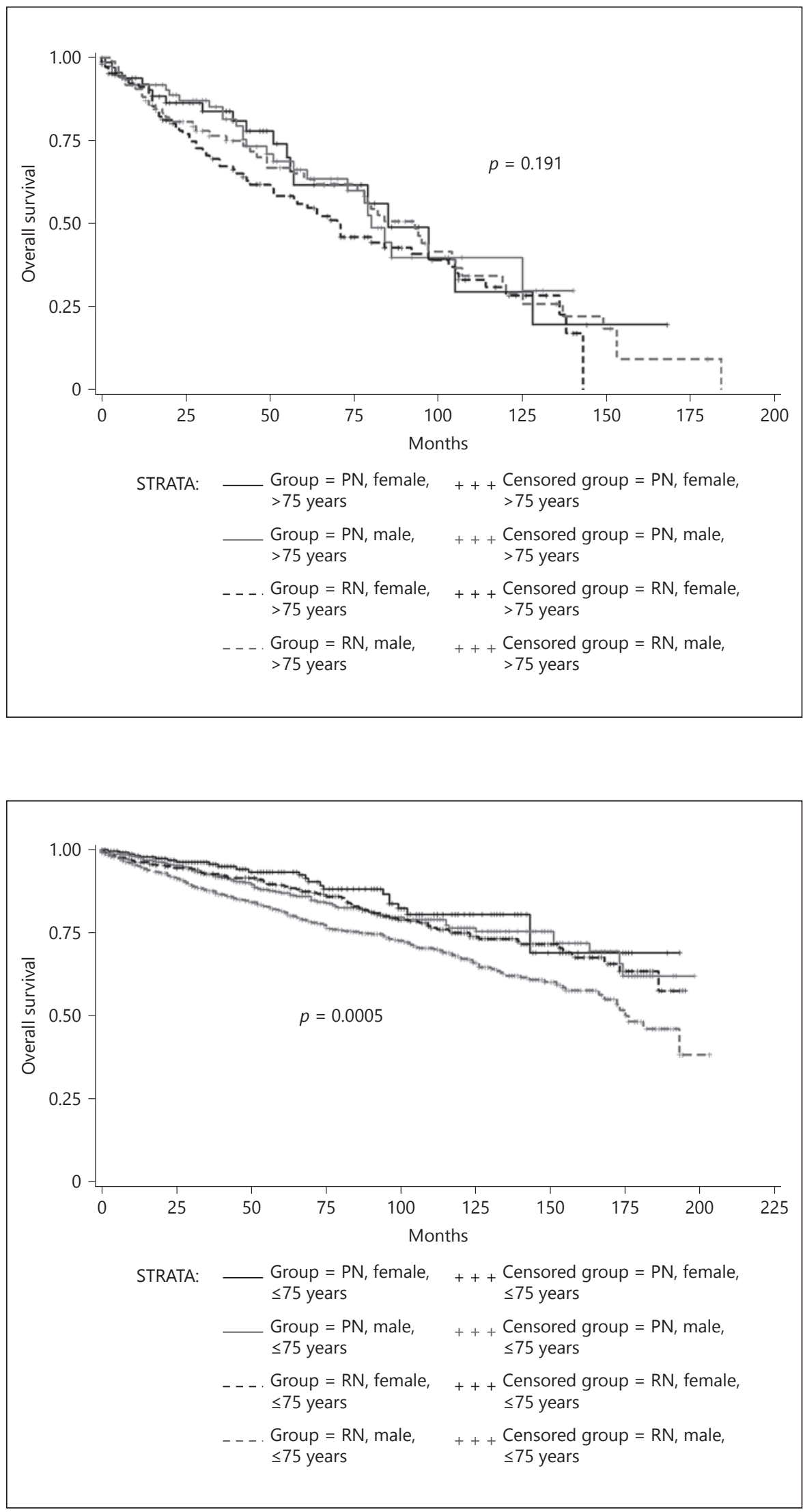

Urol Int 
Fig. 8. Overall survival of all T1 RCC patients after partial nephrectomy between 2000-2005 and 2006-2015.

Fig. 9. Overall survival of all T1 RCC patients after both radical and partial nephrectomy during 2000-2005.

Fig. 10. Overall survival of all T1 RCC patients after both radical and partial nephrectomy during 2006-2015.
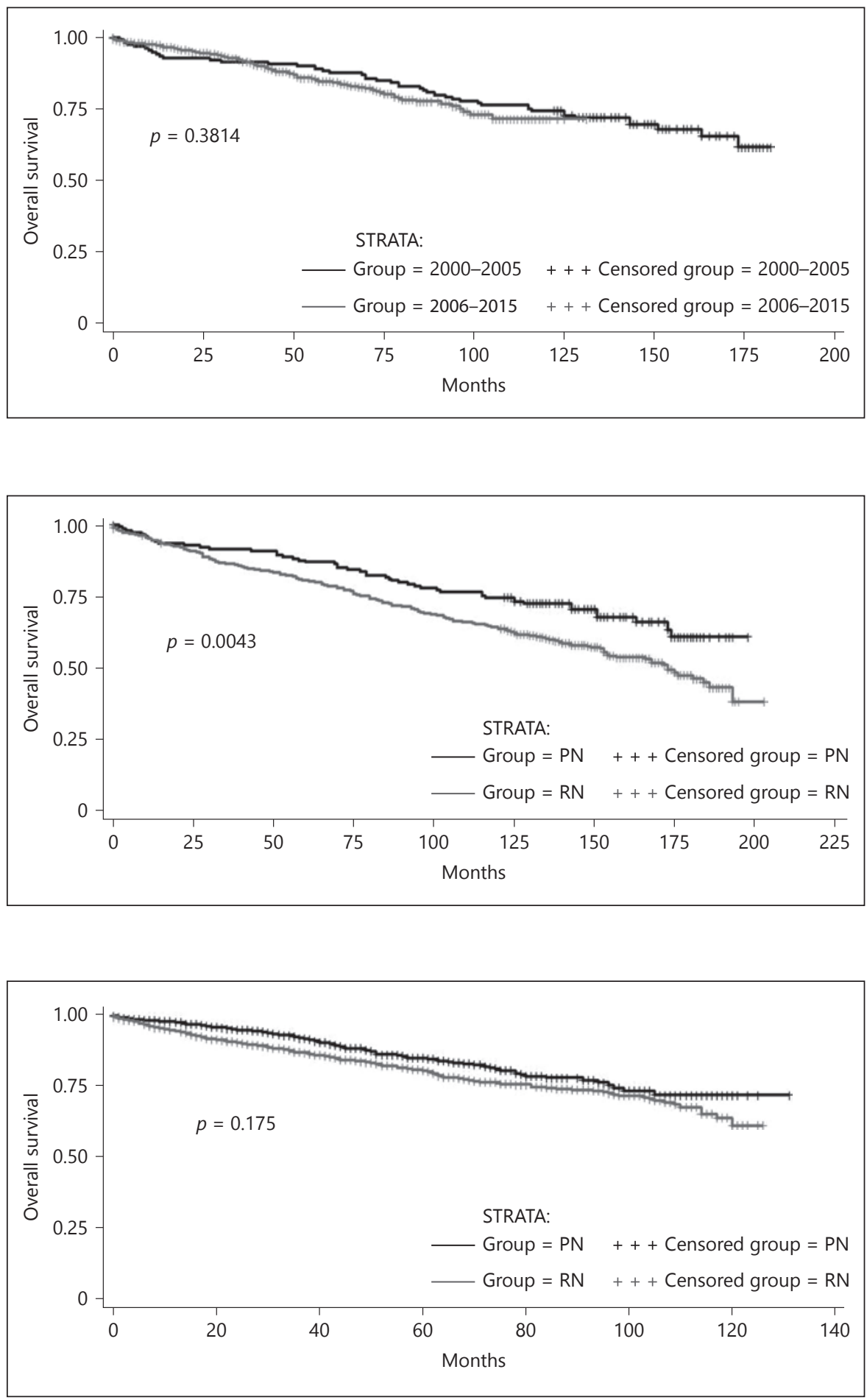

\section{Discussion}

The data from our analysis led to the recognition that in our region the guideline recommendations in order to organ confined T1 RCC are implemented well. We were able to show that within the last 10 years, the rate of PN rose from about $27 \%$ up to about $82 \%$ in T1 tumours, which is consistent with international trends [14-17].

Regardless of age and gender, in our study, we found an overall survival benefit for all patients treated by PN. 
But this significant overall survival benefit was caused only by male patients. In female patients, there was no significant overall survival benefit. Regarding the overall survival benefit after PN in patients with T1 RCC across all age groups, our findings are compliant to the literature $[5,11,13,18-20]$. Concerning the patients' age there was only a significant overall survival benefit in PN for patients younger than 75 years according to the survey of Sun et al. [11] and Tan et al. [13]. This result was reflected only in our male patients group. In women, we were not able to show a statistically significant overall survival benefit for PN independent of age. Other studies found a survival benefit for $\mathrm{PN}$ to be the greatest in patients under the age of 75 years [13]. In our study cohort, we were not able to reproduce these results, as we found a survival benefit with $\mathrm{PN}$ only in male patients up to 75 years (male $\leq 75$ years: $p=0.0005$ ).

To exclude a bias caused by learning curves in all centres, we evaluated different periods for the $\mathrm{PN}$ group. We have not seen statistically significant differences in OS for PN between the groups performed during the periods 2000-2005 (learning period) and 2006-2015 ( $p=0.3814$; Fig 8 ). Thus, in our study, the learning curve had no influence on OS.

A statistically overall survival benefit for PN was seen only with longer follow-up (mean: 126 months) of patients treated during 2000-2005 ( $p=0.0043$; Fig. 9), but not for PN performed during 2006-2015 ( $p=0.175$, mean follow up time 45 months; Fig. 10). Thus, it seems to be a fact that a minimal life expectancy of more than 45 months is necessary to feel an overall survival benefit of PN.

The overall survival of female patients $\leq 75$ years after $\mathrm{RN}$ did not differ from the OS in male patients $\leq 75$ years after PN. Thus, in our study, all overall survival benefit of nephron-sparing surgery in T1 RCC was caused by male patients $<75$ years.

Tobert et al. [21] have shown in a comprehensive English-language literature review that surgically induced reduction in glomerular filtration rate may have less impact on survival than chronic kidney disease caused by medical diseases and this may provide a biologic explanation for these seemingly disparate results.

These results indicate that the protective effect of $\mathrm{PN}$ for long-term complications like chronic kidney failure or cardiovascular disease in the elderly is overestimated. Sun et al. [11] already reported an equal OCM rate for PN and RN. Consequently, other criteria are more relevant in the decision of radical versus nephron-sparing tumour surgery in elderly patients with small kidney tumours. We

have to include other facts like the expected survival of the patients, especially considering that there might be a higher reported perioperative complication rate with PN in comparison to $\mathrm{RN}$ [22-25].

Intriguingly, some studies describe a pre-selection in PN patients being "more likely to be younger, male [...]" $[11,13,18]$ which might be a hint of a biased selection strategy.

\section{Conclusion}

In conclusion, our results warrant reconsideration of the international guidelines on the necessity of performing a partial over a RN. The next question could be: should we always seek to perform a PN in T1 RCC at any rate or might it be wiser to take into account the age and life expectancy of a patient before deciding one way or the other. A rigorous patient selection process has to involve both the co-morbidity status and life expectancy simultaneously in order to make viable decisions with respect to cancer treatment and tolerability. From our study, we believe that nephron-sparing surgery in female patients and patients who are more than 75 years old appears to have less of a benefit over RN. Additionally high-quality studies will help provide a better understanding of this problem.

\section{Disclosure Statement}

The authors declare that there are no conflicts of interest to disclose.

References

Urol In DOI: $10.1159 / 000486627$
T1 RCC after Nephron-Sparing Surgery

Depends on Gender and Age
1 Janzen NK, Kim HL, Figlin RA, Belldegrun AS: Surveillance after radical or partial nephrectomy for localized renal cell carcinoma and management of recurrent disease. Urol Clin North Am 2003;30:843-852.

$\checkmark 2$ Frank I, Blute ML, Cheville JC, Lohse CM, Weaver AL, Zincke H: An outcome prediction model for patients with clear cell renal cell carcinoma treated with radical nephrectomy based on tumor stage, size, grade and necrosis: the SSIGN score. J Urol 2002;168: 2395-2400.

- 3 Lam JS, Shvarts O, Leppert JT, Pantuck AJ, Figlin RA, Belldegrun AS: Postoperative surveillance protocol for patients with localized and locally advanced renal cell carcinoma based on a validated prognostic nomogram and risk group stratification system. J Urology 2005;174:466-472; discussion 472; quiz 801 
4 Patard JJ, Shvarts O, Lam JS, Pantuck AJ, Kim HL, Ficarra V, Cindolo L, Han KR, De La Taille A, Tostain J, Artibani W, Abbou CC, Lobel B, Chopin DK, Figlin RA, Mulders PF, Belldegrun AS: Safety and efficacy of partial nephrectomy for all T1 tumors based on an international multicenter experience. J Urol 2004;171:2181-2185, quiz 2435.

5 Zini L, Perrotte P, Capitanio U, Jeldres C, Shariat SF, Antebi E, Saad F, Patard JJ, Montorsi F, Karakiewicz PI: Radical versus partial nephrectomy: effect on overall and noncancer mortality. Cancer 2009;115:1465-1471.

-6 Lau WK, Blute ML, Weaver AL, Torres VE, Zincke H: Matched comparison of radical nephrectomy vs nephron-sparing surgery in patients with unilateral renal cell carcinoma and a normal contralateral kidney. Mayo Clin Proc 2000;75:1236-1242.

7 Sun M, Trinh QD, Bianchi M, Hansen J, Hanna N, Abdollah F, Shariat SF, Briganti A, Montorsi F, Perrotte P, Karakiewicz PI: A non-cancer-related survival benefit is associated with partial nephrectomy. Eur Urol 2012; 61:725-731.

8 Ljungberg B (Chair, Bex A (Vice-chair), Canfield S, Dabestani S (Guidelines Associate), Giles RH (Patient Advocate), Hofmann F (Guidelines Associate), Hora M, Kuczyk MA, Lam T, Marconi L (Guidelines Associate), Merseburger AS, Powles T, Staehler M, Volpe A: Guidelines on renal cell carcinoma. Eur Assoc Urol 2015

9 Ljungberg B (Chair), Bex A (Vice-chair), Canfield S, Giles RH (Patient Organisation Representative), Hora M, Kuczyk MA, Lam T, Merseburger AS, Powles T, Staehler M, Volpe A, Guidelines Associates: Dabestani S, SFPM, Hofmann F, Marconi L, Tahbaz R: EAU Guidelines on Renal Cell Carcinoma (limited text update march 2016), 2016.

10 Leitlinienprogramm Onkologie (Deutsche Krebsgesellschaft DK, AWMF): Diagnostik, Therapie und Nachsorge des Nierenzellkarzinoms, Langversion 1.0, 2015, AWMF Registernummer: 043/017OL, http://leitlinienpro-
gramm-onkologie.de/Leitlinien.7.0.html (Zugriff am: TT.MM.JJJJ).

11 Sun MB, Bianchi M, Trinh QD, Hansen J, Abdollah F, Hanna N, Tian Z, Shariat SF, Montorsi F, Perrotte P, Karakiewicz PI: Comparison of partial vs radical nephrectomy with regard to other-cause mortality in T1 renal cell carcinoma among patients aged $\geq 75$ years with multiple comorbidities. BJU Int 2012;111:67-73.

12 Lane BR, Abouassaly R, Gao T, Weight CJ, Hernandez AV, Larson BT, Kaouk JH, Gill IS, Campbell SC: Active treatment of localized renal tumors may not impact overall survival in patients aged 75 years or older. Cancer 2010;116:3119-3126.

13 Tan HJ, Norton EC, Ye Z, Hafez KS, Gore JL, Miller DC: Long-term survival following partial vs radical nephrectomy among older patients with early-stage kidney cancer. JAMA 2012;307:1629-1635.

14 Sun M, Abdollah F, Bianchi M, Trinh Q-D, Jeldres C, Thuret R, Tian Z, Shariat SF, Montorsi F, Perrotte P, Karakiewicz PI: Treatment management of small renal masses in the $21 \mathrm{st}$ century: a paradigm shift. Ann Surg Oncol 2012;19:2380-2387.

15 Zini L, Patard JJ, Capitanio U, Mejean A, Villers A, de La Taille A, Ficarra V, Crepel M, Bertini R, Salomon L, Verhoest G, Perrotte P, Bensalah K, Arjane P, Biserte J, Montorsi F, Karakiewicz P: The use of partial nephrectomy in european tertiary care centers. Eur J Surg Oncol 2009;35:636-642.

16 Dulabon LM, Lowrance WT, Russo P, Huang WC: Trends in renal tumor surgery delivery within the United States. Cancer 2010;116: 2316-2321.

17 Dash A, Vickers AJ, Schachter LR, Bach AM, Snyder ME, Russo P: Comparison of outcomes in elective partial vs radical nephrectomy for clear cell renal cell carcinoma of 4-7 cm. BJU Int 2006;97:939-945.

18 Huang WC, Elkin EB, Levey AS, Jang TL, Russo P: Partial nephrectomy versus radical nephrectomy in patients with small renal tumors-is there a difference in mortality and cardiovascular outcomes? J Urol 2009;181: 55-61; discussion 61-52.

19 Miller DC, Schonlau M, Litwin MS, Lai J, Saigal CS: Renal and cardiovascular morbidity after partial or radical nephrectomy. Cancer 2008;112:511-520.

20 Huang WC, Levey AS, Serio AM, Snyder M, Vickers AJ, Raj GV, Scardino PT, Russo P: Chronic kidney disease after nephrectomy in patients with renal cortical tumours: a retrospective cohort study. Lancet Oncol 2006;7: 735-740.

21 Tobert CM, Riedinger CB, Lane BR: Do we know (or just believe) that partial nephrectomy leads to better survival than radical nephrectomy for renal cancer. World J Urol 2014;32:573-579.

22 Van Poppel H, Da Pozzo L, Albrecht W, Matveev V, Bono A, Borkowski A, Colombel M, Klotz L, Skinner E, Keane T, Marreaud S, Collette S, Sylvester R: A prospective, randomised eortc intergroup phase 3 study comparing the oncologic outcome of elective nephron-sparing surgery and radical nephrectomy for lowstage renal cell carcinoma. Eur Urolgy 2011; 59:543-552.

23 Tan HJ, Wolf JS Jr, Ye Z, Hafez KS, Miller DC: Population level assessment of hospital based outcomes following laparoscopic versus open partial nephrectomy during the adoption of minimally invasive surgery. J Urol 2014;191: 1231-1237.

-24 Shah PH, Moreira DM, Patel VR, Gaunay G, George AK, Alom M, Kozel Z, Yaskiv O, Hall SJ, Schwartz MJ, Vira MA, Richstone L, Kavoussi LR: Partial nephrectomy is associated with higher risk of relapse compared with radical nephrectomy for clinical stage $\mathrm{T} 1 \mathrm{re}-$ nal cell carcinoma pathologically up staged to T3a. J Urol 2017;pii:S0022-5347(17)35379-X.

25 Shekarriz B, Upadhyay J, Shekarriz H, de Assis Mendes Goes F Jr, Bianco FJ, Tiguert R, Gheiler E, Wood DP Jr: Comparison of costs and complications of radical and partial nephrectomy for treatment of localized renal cell carcinoma. Urology 2002;59:211-215. 